\title{
Proceeding
}

Supplementary Issue: Winter Conferences of Sports Science. Costa Blanca Sports Science Events, 22-23 March 2021. Alicante, Spain.

\section{Types of school students based on the individualized risks of socio-psychological safety of the sports and educational environment}

\author{
ELVIRA N. GILEMKHANOVA \\ Department of Pedagogical Psychology, Kazan (Volga Region) Federal University, Kazan, Russian \\ Federation
}

\begin{abstract}
The object of this paper is to define categories of students which differ by efficiency of interaction (adaptation) in "student-the sociocultural environment of school" system on the basis of assessment of the dominating risks of sociopsychological safety. The basis of this study is an Environmental Approach, which allowed us to develop ideas about the inextricable unity of external (contextual) and internal (subject) factors of the educational environment determining the socio-psychological safety of the school. Our central concept in the framework of this approach is the analysis of the efficiency of students' interaction from a "student-the sociocultural environment of school" system. This concept formed the basis of the author's technique "Adolescence Socio-Cultural Safety Index". Technique "Adolescence SocioCultural Safety Index" possesses the necessary psychometric characteristics that allow the use of the questionnaire to identify the risks of the student's educational environment. The study involved 3,232 students in secondary education. Results: 5 types of students are revealed on the basis of cluster analysis. Each type is characterized by specifics of interaction within the "student-the sociocultural environment of school" system. Identification of type of the student opens an opportunity for individualization of educational process and realization of timely preventive measures for prevention of socio-psychological disadaptation of students. The scientific novelty of this research consists in the presentation one of the ways to solve the problem of the individualization of the educational process and the prevention of negative social phenomena in schools. Proposed method consists in differentiation of students according to the type of their dominating risk in the field of socio-psychological safety of the educational environment.

Keywords: Socio-psychological safety; Socio-psychological vulnerability; Disintegration; Virtual autism; Sports and educational environment.

Cite this article as:

Gilemkhanova, E.N. (2021). Types of school students based on the individualized risks of socio-psychological safety of the sports and educational environment. Journal of Human Sport and Exercise, 16(3proc), S1188-S1196. https://doi.org/10.14198/jhse.2021.16.Proc3.35

Corresponding author. Department of Pedagogical Psychology, Kazan (Volga Region) Federal University, Kazan, Russian Federation.

E-mail: enkazan@mail.ru

Abstract submitted to: Winter Conferences of Sports Science. Costa Blanca Sports Science Events, 22-23 March 2021. Alicante, Spain.

JOURNAL OF HUMAN SPORT \& EXERCISE ISSN 1988-5202.

(c) Faculty of Education. University of Alicante.

doi:10.14198/jhse.2021.16.Proc3.35
\end{abstract}

S1188 | 2021| Proc3 | VOLUME 16

(c) 2021 University of Alicante 


\section{INTRODUCTION}

A dramatic increase in the spread of different aggressive behaviour patterns emerging in the course of interaction between various actors of teaching and learning activities has shown the importance and necessity to develop effective ways of ensuring socio-psychological safety in educational environment.

Having analysed the existing classifications by efficiency interaction, including those in the educational environment, most often scientists turn to classification coping-strategies by R.S. Lazarus (1999) or the Thomas-Kilmann Model (Kilmann \& Kilmann, 1976). However, these classifications do not reflect modern teenager victimization trends at school. At the same time, it is important to note that cases of indirect psychological aggression among actors of school activities are increasing. For example, $22 \%$ of students in the United States have found themselves in one of the associated roles - aggressor or victim at some moment during compulsory school education (Sanchez et al., 2019). In the European context, prevalence has been reported at between 20\% and 30\% (Sanchez et al., 2019).

Therefore, the rapid transformation of contemporary reality instigated disparity between socially important scientific and educational outputs and theoretical insights. One of these underdeveloped areas relates to the modern classification of students depending on their problems of interaction in schools with weak sociopsychological safety. The analysis of this scientific problem made it possible to specify the issues of this study:

1) What could become a theoretical basis for types of school students based on the individualized risks of socio-psychological safety of the educational environment?

2) What characteristics of interaction are inherent in students with different types of individualized risks of socio-psychological safety of the educational environment?

The Environmental Approach is the basic theoretical and methodological platform for research. The need to combine human and environmental behaviour into a single system is a central idea in the works of environmental psychology founder R.G. Barker and H.F. Wright (1968). Within this framework (Barker \& Wright, 1968; Bronfenbrenner, 1979), we consider the educational environment from the position of open system of interaction between the student and the sociocultural environment of the school, while the student is defined as the subject level of the education system, and the sociocultural environment of the school as the context level (Robers et al., 2013; Wormington et al., 2012). Thus, the educational environment is the space for organizing the interaction of these two levels in an open dynamic "student-sociocultural school environment" system. The result of this interaction is the achievement of agreement or dynamic equilibrium of goals and values (as well as meanings) in this system, which is also consistent with our understanding of dynamic socio-psychological adaptation (Gilemkhanova, 2019). From this position, the socio-psychological safety of a student describes the degree and nature of the observance of the values, meanings and integrity of students in sociocultural environment at schools as a spatial organization of this interaction.

In previous studies, we described the influence of the contextual level of the educational system, which consisted in establishing the role of psychological and pedagogical, economic, social and geographical factors (Gilemkhanova, 2017). However, the developed regression model of contextual socio-cultural factors of the educational environment accounts for less than $10 \%$ of the variability of the student's sociopsychological safety index (Gilemkhanova, 2019). We assume that the influence of contextual factors is mediated by the type of personality of the student, which is formed in a specific educational environment, depending on the specific risks of the socio-cultural environment of the school. Therefore, purpose of the study is to define categories of students which differ by efficiency of interaction (adaptation) in "student-the 
sociocultural environment of school" system on the basis of assessment of the dominating risks of sociopsychological safety. To achieve this, an instrument was designed through which opinions regarding key aspects of the problem originating from diversity and the relationship of these aspects with problems of sociopsychological safety, could be more closely examined. This instrument is based on the author's understanding of the individualized risks of the educational environment's safety. The individualized risks of the socio-psychological safety of the educational environment are defined as the personal characteristics of the subject of the educational process, causing the complexity of interaction in the system "studentsociocultural environment of the school".

The hypothesis of the study: on the basis of an individualized assessment of the dominant risks of sociopsychological safety in the educational environment, it is possible to distinguish categories of students that differ in the specifics of interaction within the framework of the "subject of the educational processsociocultural environment of the educational organization".

\section{Literature review}

School safety studies focus on physical security. For example: Challenges in dropping off and picking up children, Challenges in physical facilities, Challenges in outdoor play space and equipment, Challenges with school compounds, Challenges with firefighting equipment and first aid kits, Challenges concerning water and sanitation, Challenges for school feeding programs (Mwoma, Begi \& Murung, 2018). A safe and secure learning environment is largely conceptualized as protecting children from physical harm, perceived as an adult duty to provide a safe physical environment for children to learn (Saltmarsh, Klopper \& Barr, 2009). At the same time, cases of indirect psychological aggression among participants in the educational process are increasing. Using a representative sample of nearly 16,000 high 6 - 10 students, T.R. Nansel et al. (2001) found that nearly $30 \%$ of respondents had involvement in bullying, either as a victim, offender, or both victim and offender during the final term of their school year. According to the latest estimates from the National Centre for Education Statistics, which studies victimisation, 14\% of students aged 12 to 18 reported being bullied for 6 months prior to the survey (DeVoe \& Kaffenberger, 2005). Such youth often struggle with dysfunctional coping styles, cognitive and emotional deficits, absence of social support, and patterns of increased risk taking (Finkelhor, 2008). Another study shows that young people reporting socio-psychological safety issues discover victimization problems both online and offline, have life adversity, trauma symptomatology, and delinquency (Mitchell et al., 2011). Thus, it can be argued that the socio-psychological safety of the school 's educational environment is a significant public health problem with consequences for mental and physical wellbeing now.

\section{MATERIALS AND METHODS}

The sample used for data collection was formed of 3,232 students aged between 12 and 16 years, who were undertaking compulsory secondary education at 36 schools of the Republic of Tatarstan (Russia). The sample is formed of $50 \%$ females and $45 \%$ males. The distribution of data reported by participants is presented in Table 1.

Table 1. Frequencies for the demographic variables according to sex.

\begin{tabular}{llccc}
\hline Gender & & Frequent & $\%$ & Valid \% \\
\hline \multirow{4}{*}{ Valid } & Men & 1455 & 44 & 45 \\
& Women & 1617 & 51 & 51 \\
& N/A & 159 & 5 & 4 \\
& $\mathrm{~T}$ & 3233 & 100 & 100 \\
\hline
\end{tabular}




\section{RESULTS AND DISCUSSION}

Cluster analysis was performed, which allowed us to identify 5 clusters (Table 2, Table 3).

Table 2. Euclidean distances between clusters.

\section{Cluster Number Distances below diagonal Squared distances above diagonal}

No. 1

No. 2

No. 3

No. 4

No. 5

\begin{tabular}{ccccc}
\hline No. 1 & No. 2 & No. 3 & No. 4 & No. 5 \\
\hline 0.00 & 13.36 & 25.96 & 15.40 & 14.94 \\
3.66 & 0.00 & 27.99 & 12.30 & 19.18 \\
5.09 & 5.29 & 0.00 & 23.55 & 67.65 \\
3.92 & 3.51 & 4.85 & 0.00 & 20.59 \\
3.87 & 4.38 & 8.23 & 4.54 & 0.00 \\
\hline
\end{tabular}

Table 3. Analysis of variance.

\begin{tabular}{lcccccc}
\hline & Between & df & Within & df & F & sig. \\
\hline Socio-psychological vulnerability & 40647.54 & 4 & 22670.55 & 3,227 & 1446.475 & .00 \\
Disintegration & 25243.97 & 4 & 20699.00 & 3,227 & 983.892 & .00 \\
Virtual autism & 47078.79 & 4 & 22608.93 & 3,227 & 1679.903 & .00 \\
Index & 8879.38 & 4 & 4134.64 & 3,227 & 1732.541 & .00 \\
\hline
\end{tabular}

Information on each cluster is presented in the Table 4.

Table 4. Descriptive statistics on clusters.

\begin{tabular}{|c|c|c|c|c|c|c|c|c|c|c|c|c|c|c|c|}
\hline \multirow[t]{2}{*}{ Variable } & \multicolumn{3}{|c|}{$\begin{array}{l}\text { Cluster } 1 \\
\mathrm{~N}=737 \text { cases }\end{array}$} & \multicolumn{3}{|c|}{\begin{tabular}{|l} 
Cluster 2 \\
$\mathrm{~N}=502$ cases
\end{tabular}} & \multicolumn{3}{|c|}{$\begin{array}{l}\text { Cluster } 3 \\
\mathrm{~N}=468 \text { cases }\end{array}$} & \multicolumn{3}{|c|}{$\begin{array}{l}\text { Cluster } 4 \\
\mathrm{~N}=533 \text { cases }\end{array}$} & \multicolumn{3}{|c|}{\begin{tabular}{|l|} 
Cluster 5 \\
$\mathrm{~N}=992$ cases
\end{tabular}} \\
\hline & $\mathrm{M}$ & $S$ & V & $M$ & $S$ & $\mathrm{~V}$ & $M$ & $S$ & $\mathrm{~V}$ & $M$ & $S$ & V & $M$ & $S$ & V \\
\hline & 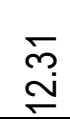 & $\stackrel{?}{\sim}$ & 咸 & 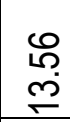 & $\underset{\substack{\infty \\
\text { N }}}{ }$ & יָ & 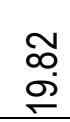 & 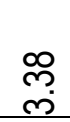 & $\stackrel{\text { P }}{F}$ & 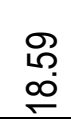 & $\stackrel{\circ}{\sim}$ & $\underset{\substack{\mathbb{0} \\
\text { d }}}{ }$ & চ̋ & $\underset{\mathrm{d}}{\mathrm{d}}$ & $\begin{array}{l}\infty \\
i \\
i \\
i\end{array}$ \\
\hline Disintegration & $\stackrel{ }{\circ}$ & $\widetilde{\widetilde{N}}$ & $\underset{\substack{n \\
i}}{i}$ & $\begin{array}{l}\text { S్ } \\
\text { S్ర }\end{array}$ & $\underset{i}{\sigma}$ & $\underset{\substack{\infty \\
0}}{0}$ & $\begin{array}{l}8 \\
0 \\
10\end{array}$ & 实 & 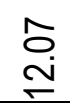 & $\stackrel{\mathscr{O}}{\rightleftarrows}$ & م & $\underset{0}{R}$ & $\begin{array}{l}\delta \\
\infty\end{array}$ & $\underset{\text { i }}{\text { in }}$ & $\stackrel{0}{\dot{\sigma}}$ \\
\hline Virtual autism & $\frac{\mathscr{L}}{\stackrel{5}{\sigma}}$ & $\stackrel{\mathbb{L}}{\mathrm{L}}$ & fे & $\begin{array}{l}\infty \\
\stackrel{+}{\leftarrow}\end{array}$ & $\stackrel{0}{i}$ & 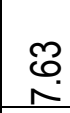 & 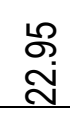 & $\stackrel{m}{m}$ & $\frac{9}{\infty}$ & $\begin{array}{l}\stackrel{\infty}{\infty} \\
\stackrel{+}{+}\end{array}$ & $\begin{array}{l}\infty \\
\substack{\infty \\
\sim}\end{array}$ & م) & 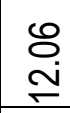 & $\stackrel{\mathscr{N}}{\sim}$ & $\begin{array}{l}8 \\
0 \\
10\end{array}$ \\
\hline Index & $\stackrel{g}{\underset{I}{\simeq}}$ & $\stackrel{6}{\check{2}}$ & $\stackrel{\widetilde{m}}{\check{r}}$ & 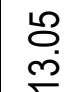 & 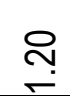 & $\stackrel{f}{\stackrel{f}{r}}$ & 宫 & 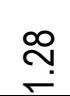 & ஜֶ. & $\stackrel{m}{\ddot{p}}$ & $\stackrel{ }{ }$ & $\stackrel{\bar{̣}}{\sim}$ & f. & $\stackrel{\widetilde{\sigma}}{\Gamma}$ & $\stackrel{2}{0}$ \\
\hline
\end{tabular}

Note: M-Mean; S-Standard; V-Variance.

Based on the graphical representation of the cluster analysis results, 5 student profiles were distinguished, differing in the configuration of the risks of socio-psychological safety in the educational environment (Figure1). 


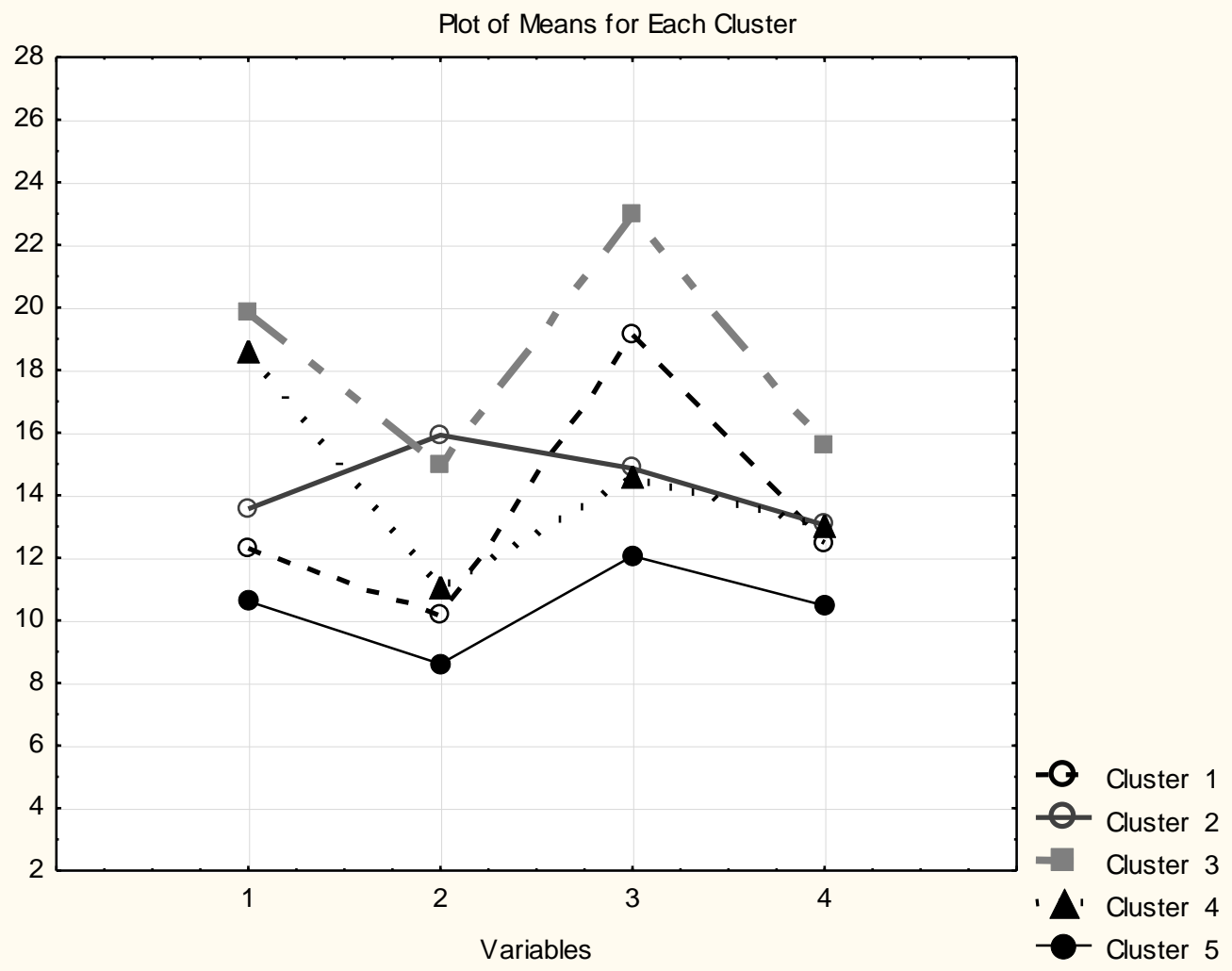

Note 1. Socio-psychological vulnerability; 2- Disintegration; 3 - Virtual autism; 4 - Index of socio-psychological safety.

Figure 1. Student profiles based on socio-psychological safety risk configuration.

Cluster analysis allowed to distinguish 5 types of profiles. Cluster 5 profile can be described as a low risk profile with violations of socio-psychological safety. This is the most favourable type of students in relation to the nature of their interaction with the educational environment. It includes about a third of the students. This type of students is focused on productive cooperation, subject position, communicative activity and efficiency, psychologically comfortable well-being in school and class. Cluster 3 profile is characterized by a matching configuration profile with the most pronounced values on the scales, as opposed to profile 5 . This type of students is characterized by pronounced psychological safety difficulties in all three parameters: sociopsychological vulnerability, disintegration and virtual autism. This type of students is characterized by autoaggressive tendencies, a tendency to self-deprecation, a high level of victimization, problems in interaction with other participants in the educational process. They feel not included in the informal structure of classroom relationships and experience psychological discomfort at school. Against this background, the problems of communication and self-identification determine the high level of virtual autisation of this type of students. Students belonging to this cluster can be identified as at risk for social and psychological maladjustment at school. Their percentage is approximately $15 \%$ of all students.

Profiles 1, 2 and 4 differ in configurations, but they have practically the same level of risk of sociopsychological safety, varying on a scale that shows the upper peak, that is, according to the prevailing risk. A distinctive characteristic of profile 1 is the high level of virtual autisation. Virtual autism is defined by the author as a variant of socio-psychological maladjustment as a result of disturbed social interaction, expressed in the preference of impersonal communication, problems of self-identification, marginal identity and 
non- productive reflection. Such students are characterized by weak purposefulness and perseverance, low potential for coping with external situations.

A distinctive feature of profile 2 is a high level of disintegration. Problems of psychological safety within the educational environment are associated with the mismatch of individual mental introjects and dispositions with the background characteristics of the educational environment and subjects of the educational process. The key risk is isolation, alienation, which also determines inertia and non-inclusion in the educational system.

A distinctive feature of profile 4 is a high level of socio-psychological vulnerability. This characteristic is associated with passivity, compliance with external influence, hypersensitivity to the nuances of social interaction. The problems of the socio-psychological interaction between the student and other subjects of the educational system are expressed in self-destructive tendencies, the direction of destructive impulses towards themselves, and is accompanied by feelings of guilt, touchiness, increased anxiety. The main characteristics include loss of integrity, negative self-concept, increased susceptibility to external evaluation and influence, as well as suggestibility.

Based on the analysis of profiles, the types of students were named. 1-Autistic type; 2- Disintegrated type; 3 - Maladaptive type; 4 - Vulnerable type; 5 - Adaptive type.

According to I.M. Sanchez et al. (2019) the influence of the climate at the school is a contextual factor of risk of School bullying and can indicate the disturbed social and psychological safety of the educational environment. Our study also supports the key conclusion of foreign colleagues that the quality of relationships established by a person with their environment is one of the key indicators of their susceptibility to the risks of the social and cultural environment of a school. Acceptance at school (in our case - is the data scale of social and psychological disintegration) - is a protective factor against victimization. I.M. Sanchez's et al. (2019) concept of coexistence is used as central. It was shown that the concept of coexistence is associated with such elements of public relations as respect and tolerance that determine the quality of psychological climate.

The study covered the efficiency of cooperation, established by students with the educational environment. It was shown that the effectiveness of interaction is associated with individualized risks of the sociopsychological safety of the socio-cultural environment of the school. This is consistent with studies conducted by M.K. Demaray \& C.K. Malecki (2003) and M.E. Schmidt and C.L. Bagwell (2007), who demonstrated that the acceptance at school - is a protective factor against victimization risks.

On the other hand, a study by M. Cava (2011) showed that students who maintain relationships with less popular groups and are ignored by peers, are more likely to suffer from school destructions. This agrees with the findings presented by S. Andres and A. Barrios (2009), who stated the importance of effective interaction in the school environment.

Similar data was provided by J. Acosta et al (2018) who identified four elements that need to be addressed by analysing a favourable school environment:. Inter relationships, self-confidence, empathy and human integration in school. Human integration is one of the aspects most emphasized by the academic literature studied in studies such as those developed by M. Cava (2011) and S. Andres and A. Barrios (2009). In our study, among the key risks of the educational environment, which determined our classification of the type of students are also highlighted such aspects as disintegration, vulnerability and isolation. 


\section{Findings}

The specific social and cultural environment of the school forms a certain type of personality depending on the subjective assessment of the degree of psychological safety of the educational environment.

The analysis of the student assessment of the sociocultural risks of the educational environment made it possible to identify 5 types of students: 1-Autistic type; 2-disintegrated type; 3-maladaptive type; 4-Vulnerable type; 5 Adaptive types. Each type has a specific interaction within the "student-socio-cultural school environment" system.

A key feature of the autistic type is the preference of the impersonal communication, problems of selfidentity, marginal identity, unproductive reflection.

The key feature of the disintegrated type is the mismatch of individual mental introjects and dispositions with the background characteristics of the educational environment and other subjects of the educational process.

A key feature of the vulnerable type is the direction of the destructive impulses on themselves, feeling of guilt, touchiness, increased anxiety.

A key feature of the maladaptive type is the pronounced complexity of socio-psychological adaptation, characterized by a mosaic combination of the features of the types described above.

\section{CONCLUSION}

The significance of the study is determined by modern trends in the search for adequate mechanisms for the individualization of the educational process and the prevention of negative social phenomena in the educational environment. One of the ways to solve this problem is to differentiate students according to the type of risk of socio-psychological safety of the educational environment. Identification of the type of dominant risks of socio-psychological safety provides an opportunity to implement timely preventive measures to avoid social and psychological maladjustment of students. In addition, further studies will show that these typological features mediate and organize motivational component of the educational activity that triggers the need to consider the activity of students in the context of interaction of the individual in the system "subject of the educational process, socio-cultural environment of the educational organization".

\section{Limitation and study forward}

This study was conducted only on students in Russian secondary schools. While this research can be done globally to confirm the presented typologization on other samples for more general results. It is also important to conduct long-term studies to determine the sustainability of the identified typological features, which is our prospect for further study.

\section{ACKNOWLEDGMENTS}

The work is performed according to the Russian Government Program of Competitive Growth of Kazan Federal University. 


\section{REFERENCES}

Acosta, J., Chinman, M., Ebener, P., Malone, P.S., Phillips, A. \& Wilks, A. (2018). Understanding the relationship between perceived school climate and bullying: A mediator analysis. J. Sch. Violence, 18, 200-215. https://doi.org/10.1080/15388220.2018.1453820

Andres, S. \& Barrios, A. (2009). De la violencia a la convivencia en la escuela: El camino que muestran los estudios mas recientes. Revista Complutense de Educacion, 20, 205-229.

Barker, R.G. \& Wright, H.F. (1968). Ecological Psychology: Concepts and methods for studying the environment of human behavior. Stanford: Stanford University Press.

Bronfenbrenner, U. (1979). The Ecology of Human Development: Experiments by Nature and Design. Cambridge: Harvard University Press.

Cava, M. (2011). Familia, profesorado e iguales: Claves para el apoyo a las victimas de acoso escolar. Psychosoc. Interv, 20, 183-192. https://doi.org/10.5093/in2011v20n2a6

Demaray, M.K. \& Malecki, C.K. (2003). Perceptions of the frequency and importance of social support by students classified as victims, bullies, and bully/victims in an urban middle school. Sch. Psychol. Rev., 32, 471-490. https://doi.org/10.1080/02796015.2003.12086213

DeVoe, J.F., Kaffenberger, S. (2005). Student Reports of Bullying: Results from the 2001 School Crime Supplement to the National Crime Victimization Survey. Washington: US GPO. https://doi.org/10.1037/e428692005-001

Finkelhor, D. (2008). Childhood Victimization: Violence, Crime, and Abuse in the Lives of Young People. New York: Oxford University Press. https://doi.org/10.1093/acprof:oso/9780195342857.001.0001

Gilemkhanova, E. (2017). The interrelation of predictors of the addictive behavior of students with the basic social and economic indicators of territories. Quid-Investigacion Ciencia Y Tecnologia, 28, 739745.

Gilemkhanova, E. (2019). Technique "Index of sociocultural safety of the school student". MSU bulletin, Series 14. Psychology, 2, 164-183. https://doi.org/10.11621/vsp.2019.02.164

Katsakiori, P.G., Sakellaropoulos, G. \& Manatakis, E. (2009). Towards an evaluation of accident investigation methods in terms of their alignment with accident causation models. Safety Science, 47(7), 1007-1015. https://doi.org/10.1016/j.ssci.2008.11.002

Kilmann, W.T. \& Kilmann, R.H. (1976). Thomas-Kilmann conflict MODE instrument. https://doi.org/10.1037/t02326-000

Lazarus, R.S. (1999). Stress and emotion: A new synthesis. New York: Springer Publishing Co.

Mitchell, K.J., Finkelhor, D, Wolak, J., Michele, L.Y, Turner, H (2011). Youth Internet Victimization in a Broader Victimization Context. Journal of Adolescent Health, 48, 128-134 https://doi.org/10.1016/j.jadohealth.2010.06.009

Mwoma, T., Begi, N. \& Murung, C. (2018). Safety and security in preschools: A challenge in informal settlements. Issues in Educational Research, 28(3), 720-736.

Nansel, T.R., Overpeck, M., Pilla, R.S., Ruan, W.J., Simons-Morton, B., \& Scheidt, P. (2001). Bullying behaviors among US youth: Prevalence and association with psychosocial adjustment. JAMA: Journal of the American Medical Association, 285(16), 2094-2100. https://doi.org/10.1001/jama.285.16.2094

Republic of Kenya. (2008). Safety standards manual for schools in Kenya. Ministry of Education. First edition April 2008. Retrieved from: http://cwsglobal.org/wp-content/uploads/2017/01/CWSSSZSchools-Manual_Kenya.pdf

Robers, S., Kemp, J., Truman, J., \& Snyder, T.D. (2013). Indicators of school crime and safety: 2012 (NCES 2013-036/NCJ 241446). Washington: National Center for Education Statistics, U.S. 
Department of Education, and Bureau of Justice Statistics, Office of Justice Programs, U.S. Department of Justice.

Saltmarsh, S., Klopper, C. \& Barr, J. (2009). Early childhood safety education: An overview of safety curriculum and pedagogy in outer metropolitan, regional and rural NSW. Australian Journal of Early Childhood, 34(4) 31-36. https://doi.org/10.1177/183693910903400405

Sanchez I.M, Martinez R.G., Gonzalez D.G, Rodriguez J.A. (2019). School Bullying in Compulsory and Advanced Secondary Education. Determining Factors in its Intervention. International Journal of Environmental Research and Public Health, 16(5), 750-763. https://doi.org/10.3390/ijerph16050750

Schmidt, M.E. \& Bagwell, C.L. (2007). The protective role of friendships in overtly and relationally victimized boys and girls. Merrill-Palmer Q, 53, 439-460. https://doi.org/10.1353/mpq.2007.0021

Wormington, S.V., Anderson, K.G., Tomlinson, K.L., \& Brown, S.A. (2012). Alcohol and other drug use in middle school: The interplay of gender, peer victimization, and supportive social relationships. Journal of Early Adolescence, 33, 610-634. https://doi.org/10.1177/0272431612453650

\section{@(@) $\Theta \Theta$}

This work is licensed under a Attribution-NonCommercial-NoDerivatives 4.0 International (CC BY-NC-ND 4.0). 